\title{
Association of CAPN10 haplotype combinations with type 2 diabetes mellitus and metabolic syndrome among Egyptians: pilot study-genotyping of three CAPN10 variants
}

Shaymaa W. El-Far ${ }^{1,2^{*}} \mathbb{B}$, Heba Sh. Kassem³ ${ }^{3}$ Amira M. Embaby ${ }^{2}$, Abir A. Saad $^{2 \wedge}$, Nader Mowafy ${ }^{4}$ and Medhat Haroun ${ }^{2}$

\begin{abstract}
Background: T2DM is a polygenic, metabolic complex and multifactorial disease. Several genes contribute to risk of type 2 diabetes and metabolic syndrome among different populations.

Results: An relationship between three identified CAPN-10 variants [SNP-43 (rs\#3792267), SNP-19 (rs\#3842570) and SNP-63 (rs\#5030952)] localized on 2q37 and type 2 diabetic patients with and without metabolic syndrome (MS) have been reported in our comparative study (diabetic vs health control individuals). Genotyping of study cohorts was carried out using restriction fragment length polymorphism (RFLP-PCR). Statistical analysis of data reveals that the haplotype combination 111/112 confers a significant risk for type 2 diabetes mellitus (T2DM). Patients with the homozygous haplotype combination of 122/122 are less susceptible to MS when compared to other patients carrying other haplotype combinations. Regarding obesity, a core component in MS, the haplotype combinations 111/121 and 122/122 demonstrate a significant protective role. Furthermore, the haplotype combination 111/111 displays a significant risk for high levels of total cholesterol.

Conclusion: Present findings address that these haplotype combinations 111/112, 111/121 and 122/122 of CAPN10 SNP-43, -19 and -63 constitute unique DNA biomarker fingerprints toward susceptibility and risk for T2DM and MS among Egyptians when compared to other haplotype combinations reported in other populations of different ethnicity. To enhance the power of human evolution control nowadays, mutations and polymorphisms in target genes associated with human diseases should be well understood.
\end{abstract}

Keywords: CAPN10, Type 2 diabetes mellitus, Egyptians

\footnotetext{
*Correspondence: drshaymaa1@gmail.com; Shfar@tu.edu.sa

${ }^{1}$ Division of Pharmaceutical Microbiology, Department of Pharmaceutics

and Industrial Pharmacy, College of Pharmacy, Taif University, Taif,

Kingdom of Saudi Arabia

Abir A. Saad: deceased

Full list of author information is available at the end of the article
}

\section{Background}

T2DM is a polygenic, metabolic complex and multifactorial disease, influenced by both genetic and non-genetic factors [1]. It is characterized by impaired insulin secretion, decreased insulin sensitivity in peripheral tissues, and increased hepatic glucose production [2]. Insulin resistance is believed to be the fundamental basis of MS, characterized by clustering of hyperglycemia, 
hypertension, dyslipidemia, and obesity [3]. The prevalence of MS is known to be considerable in patients with T2DM than in general population.

Genome-wide association studies (GWAs) have identified several genes contributing to T2DM predisposition including gene encoding calpain 10 (CAPN10) [4]. It is located on chromosome 2q37.3, comprises 15 exons spanning $31 \mathrm{~kb}$ and encodes a 672 amino acids intracellular protease [5]. Calpain10 is a member of calpain superfamily which are non-lysosomal neutral cytoplasmic cysteine proteases requiring calcium ions for activity [6].

A complex relationship between diabetes susceptibility and CAPN10 polymorphisms. These variants that are grouped in a haplotype are transmitted together from parents to off springs without being subjected to recombination events.

In the present study, we examine the role of three intronic CAPN10 SNPs [SNP-43 (rs\#3792267) at intron-3, SNP-19 (rs\#3842570) at intron-6 and SNP-63 (rs\#5030952) at intron-13] at the level of genotype, haplotype and haplotype combination in relation to genetic susceptibility to both T2DM and MS among Egyptians. To the best of our knowledge, our study represents the first report exploring CAPN10-variants and T2DM-MS susceptibility among Egyptians. This study represented a highlighting point to explore T2DM genetics among Egyptian population. Understanding the cause of diabetes at the level of genetics would be a helpful tool to reduce the diabetes incidence among future generations.

\section{Method(s)}

\section{Study population and data collection}

A total of 102 individuals (49 type 2 diabetic patients and 53 healthy controls) were enrolled in this study. Characteristics of patients were matched well with World Health Organization (WHO) criteria outlined for T2DM [7]. Patients' demographic, clinical and laboratory characteristics and matched controls were taken. Age, gender, BMI, duration of diabetes, first-degree family history of diabetes, history of chronic diabetes complication, treatment of diabetes, blood pressure, fasting plasma glucose, glycated hemoglobin $(\mathrm{GHb})$ were measured. Lipid profile (Total cholesterol, triglyceride, HDL-c and LDL-c) was determined for patients' group only to fulfill the metabolic syndrome criteria.

\section{Metabolic syndrome criteria}

According to combined National Cholesterol Education Program-Adult Treatment Panel (NCEP-ATP) II [8], diabetic patients that meet 2 or 3 criteria from a total of 4 criteria were diagnosed to have MS. Criteria of MS are (1) Obesity expressed in terms of as body mass index $(\mathrm{BMI}) \geq 25 \mathrm{~kg} \mathrm{~m}^{2}$; (2) Hypertriglyceridemia $\geq 150 \mathrm{mg} /$
dL (1.693 mmol/L); (3) Low high-density lipoprotein cholesterol (HDL-c) $<40 \mathrm{mg} / \mathrm{dL}(1.034 \mathrm{mmol} / \mathrm{L})$ in men and $<50 \mathrm{mg} / \mathrm{dL}(1.293 \mathrm{mmol} / \mathrm{L})$ in women; (4) High blood pressure $\geq 130 / 85 \mathrm{mmHg}$.

\section{Isolation of genomic DNA from leukocytes}

Genomic DNA was isolated from peripheral total leukocytes as described earlier [9]. This DNA was used as a DNA template in three separate polymerase chain reactions to amplify three partial fragments containing $S N P$ 19, SNP-43 and SNP -63 in CAPN10.

\section{CAPN10 genotyping \\ SNP-19 (rs\#3842570)}

The following primer set; forward: 5'-GTTTGGTTC TCTTCAGCGTGGAG-3' and reverse: 5'-CATGAACCC TGGCAGGGTCTAAG-3' was used in PCR to amplify a partial fragment of CAPN10 containing SNP-19. PCR products were separated on $3 \%$ agarose gel. Allele 1 (two repeats of $32 \mathrm{bp}$ ) and allele 2 (three repeats of $32 \mathrm{bp}$ ) were detected as two fragments of $155 \mathrm{bp}$ and $187 \mathrm{bp}$, respectively [10, 11], (Fig. 1a).

\section{SNP-43 (rs\#3792267)}

A fragment of CAPN10 containing SNP-43 was amplified via PCR using the following primer set: forward primer: 5'-CACGCTTGCTGTGAAGTAATGC-3' and reverse primer: 5'-CTCTGATTCCCATGGTCTGTAG-3'. The resulting 144 bp PCR product was digested with NsiI (Fermentas, Fast digest). DNA segments resulting from restriction digestion reaction were separated on $3 \%$ agarose gel. Allele $1(\mathrm{G})$ was not cleaved with $N$ siI and was still $144 \mathrm{bp}$, whereas allele 2 (A) was cleaved with NsiI into two fragments $121 \mathrm{bp}$ and $23 \mathrm{bp}$ [11], (Fig. 1b).

\section{SNP-63 (rs\#5030952)}

A DNA fragment of CAPN10 containing SNP-63 was amplified using the primer set, forward: 5'-AGCACT CCCAGCTCCTGATC-3' and reverse: 5'-AGGGGG GCCAGGGCCTGACGGGGGTGGCG-3'. PCR products (192 bp) were digested with HhaI (Fermentas, Fast digest). The resulting DNA segments after restriction digestion were separated on $3 \%$ agarose gel. Allele 1 (C) was detected as a 162 bp fragment, and allele $2(\mathrm{~T})$ was detected as a $192 \mathrm{bp}$ fragment [10,11], (Fig. 1c).

\section{Statistical analysis}

Data were processed using SPSS package version 18. Descriptive statistics including frequency, distribution, mean, and standard deviation (SD) were used to describe different clinical characteristics. Chi-Square test, $t$ test and Mann-Whitney test were used to test for significance among different variables. The significance of the 

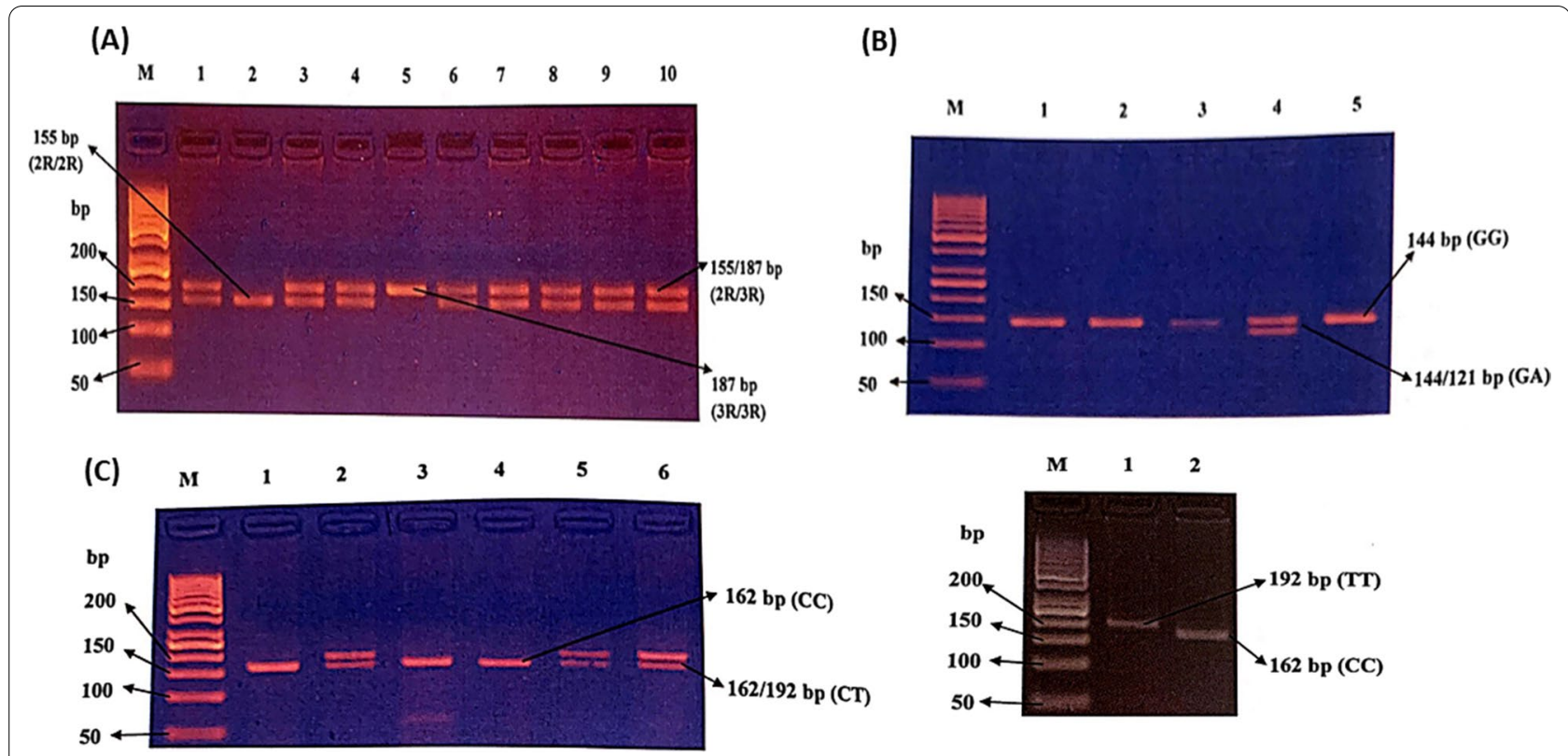

Fig. 1 Agarose gel electrophoresis (3\%) showing a PCR products of SNP-19: Lane (2) represents homozygous (2R/2R, 155 bp) of two repeats of $32 \mathrm{bp}$, Lane (5) represents homozygous $(3 R / 3 R$, $187 \mathrm{bp}$ ) of three repeats of $32 \mathrm{bp}$ and lanes $(1,3,4,6,10)$ represent heterozygous genotype(2R/3R,155 bp and 187 bp), b RFLP-PCR products of SNP-43 utilizing FastDigest ${ }^{\circledR}$ Nsil and $\mathbf{c}$ RFLP-PCR products of SNP-63 utilizing FastDigest ${ }^{\circledR}$ HhalM: 50 bp a ladder represents homozygous of three repeats

results was taken at the $5 \%$ level of significance. Odds ratio (ORs) and $95 \%$ confidence interval $(95 \% \mathrm{CI})$ were calculated for different studied parameters. An odds ratio of 1 implies that the event is equally likely in both groups (patients and controls unless otherwise stated). An odds ratio greater than one implies that the event is more likely in the patients' group; it is considered as risky factor. An odds ratio less than one implies that the event is less likely in the patients' group and is considered as preventive factor [12]. Inferences of haplotypes and haplotype combinations from genotype population data were performed using the MATLAB ${ }^{\circledR}$ version 7.10.0 (R2010a). Genotypes frequency of $S N P-43, S N P-19$, and $S N P$ -63 polymorphisms were tested for being expressed in Hardy-Weinberg equilibrium using Chi-Square test $\left(\mathrm{X}^{2}\right)$.

\section{Results}

\section{Study participants}

A total of 49 subjects with T2DM (16 men/33 women) and 53 healthy individuals $(25 \mathrm{men} / 28$ women) were enrolled in this study. Ethical Approval and informed consent had been granted. Patients diagnosed according to WHO criteria. Demographic and clinical characteristics of the study groups were compared by using the Chi-Square test ( $\mathrm{X}^{2}$ test) and $\mathrm{t}$ test. Data were expressed as mean $\pm \mathrm{SD}$ (standard deviation). Healthy individuals were frequency matched with patients according to age and gender ratio $(p>0.05)$. However, other clinical and biochemical parameters were significantly higher in diabetic patients than in control subjects $(p<0.001)$ as shown in Table 2. Twenty-six patients (53.1\%) reported positive family history of T2DM. The percent of cardiovascular complication was found $40.8 \%$ in diabetic group. Lipid profile was analyzed for patients' group only to fulfill the metabolic syndrome criteria.

\section{CAPN10 and type 2 diabetes mellitus susceptibility Allele and genotype distribution}

There were no significant differences according to allele and genotype distribution among T2DM and control groups. The genotypic frequencies were in Hardy-Weinberg equilibrium (HWE) $(p>0.05)$.

\section{Haplotype and haplotype combination distribution}

For $S N P-43$, the $\mathrm{G}$ and A alleles were coded by 1 and 2, respectively. For $S N P-19,1$ represented two repeats of the 32 bp allele and 2 represented three repeats. For $S N P-63$, the $\mathrm{C}$ and $\mathrm{T}$ alleles were coded by 1 and 2, respectively. Only Seven CAPN10 haplotypes $(111,112,121,122,211$, 221 and 222) were identified in this study. The distribution of all observed haplotypes was comparable between subjects with T2DM and healthy control subjects $(p>0.05)$ (data not shown). The expected frequencies of various haplotype combinations (also called diplotypes) for diabetes cases and control subjects were also determined, and 13 different haplotype combinations were 
detected. Among these estimated 13 haplotype combinations, the 111/121 diplotype was the most frequent diplotype among both diabetic patients and healthy controls while the 111/112 diplotype was significantly associated with a 10.15-fold higher risk of T2DM (Table 1).

\section{CAPN10 and metabolic syndrome among T2DM patients}

Diabetic cases were stratified according to metabolic syndrome criteria, patients with and without metabolic syndrome. High prevalence of the metabolic syndrome in subjects with T2DM was observed (77.6\%). High BMI value had been observed in metabolic syndrome patients compared to non-metabolic syndrome patients (Table 2).
The statistical analysis of all clinical and biochemical characteristics for both groups was performed using Chisquare test and Mann-Whitney test as shown in Table 2.

\section{Relative MS risk according to genotype, haplotype and haplotype combination frequencies of CAPN10 variants}

Patients with or without MS reported comparable distribution of genotype $(p>0.05)$. However, according to haplotype frequency, only the 122 haplotype found to be significantly lower in the patients with MS (5.3\%) compared to the patients without MS (22.7\%) (OR 0.14, $95 \%$ CI $0.02-0.9, p=0.008)$. The homozygous $122 / 122$

Table 1 Haplotype combination distribution among patients and controls

\begin{tabular}{|c|c|c|c|c|c|c|c|}
\hline \multirow{2}{*}{$\begin{array}{l}\text { Haplotype or } \\
\text { diplotype }\end{array}$} & \multicolumn{2}{|c|}{ T2DM } & \multicolumn{2}{|c|}{ Controls } & \multirow[t]{2}{*}{$\mathrm{x}^{2}$} & \multirow[t]{2}{*}{$P$} & \multirow[t]{2}{*}{ OR $(95 \% \mathrm{Cl})$} \\
\hline & Freq & $\%$ & Freq & $\%$ & & & \\
\hline $111 / 111$ & 9 & 18.4 & 11 & 20.8 & 0.092 & 0.764 & $0.86(0.3-2.5)$ \\
\hline $111 / 112$ & 8 & 16.3 & 1 & 1.9 & 6.599 & $0.011^{*}$ & $10.15(1.2-225)^{*}$ \\
\hline $111 / 121$ & 10 & 20.4 & 11 & 20.8 & 0.002 & 0.980 & $0.98(0.3-2.8)$ \\
\hline $111 / 122$ & 4 & 8.2 & 6 & 11.3 & 0.287 & 0.612 & $0.7(0.2-3.1)$ \\
\hline $111 / 221$ & 4 & 8.2 & 7 & 13.2 & 0.673 & 0.430 & $0.58(0.1-2.4)$ \\
\hline $111 / 222$ & 1 & 2 & 3 & 5.7 & 0.885 & 0.361 & $0.4(0.01-3.96)$ \\
\hline $112 / 112$ & 1 & 2 & 1 & 1.9 & 0.003 & 0.980 & $1.08(0.0-40.9)$ \\
\hline $112 / 122$ & 0 & 0 & 2 & 3.8 & 1.886 & 0.177 & $0.0(0.0-4.5)$ \\
\hline $121 / 121$ & 5 & 10.2 & 10 & 18.9 & 1.524 & 0.220 & $0.49(0.1-1.7)$ \\
\hline $121 / 221$ & 3 & 6.1 & 1 & 1.9 & 1.212 & 0.275 & $3.39(0.3-87.7)$ \\
\hline
\end{tabular}

Bold indicates statistical significant result

*Significant value at $P<0.05$

Table 2 The clinical characteristics of patients' classified according to MS

\begin{tabular}{|c|c|c|c|}
\hline Parameters & Patients with MS & Patients without MS & $p$ \\
\hline$N(M / F)$ & $38(10 / 28)$ & $11(6 / 5)$ & $X^{2}=3.09 p=0.078$ \\
\hline Age (years) & $53.1 \pm 6.8$ & $58.7 \pm 11.3$ & $Z=1.65 p=0.1$ \\
\hline BMI $\left(\mathrm{kg} / \mathrm{m}^{2}\right)$ & $32.5 \pm 4.1$ & $26.1 \pm 5$ & $Z=3.72 p<0.0001^{*}$ \\
\hline $\mathrm{SBP}(\mathrm{mmHg})$ & $139.9 \pm 26.3$ & $108.2 \pm 16$ & $Z=3.69 p<0.0001^{*}$ \\
\hline $\mathrm{DBP}(\mathrm{mmHg})$ & $86.7 \pm 10.4$ & $72.2 \pm 10.1$ & $Z=3.38 p=0.001^{*}$ \\
\hline FPG (mg/dl) & $214.4 \pm 101.1$ & $199.9 \pm 62.9$ & $Z=0.072 p=0.943$ \\
\hline $\mathrm{HbA1c}(\%)$ & $7.1 \pm 1.6$ & $7.2 \pm 2.1$ & $Z=0.36 p=0.719$ \\
\hline Total Cholesterol (mg/dl) & $164.7 \pm 52.8$ & $122.7 \pm 63.6$ & $Z=2.109 p=0.035^{*}$ \\
\hline Triglyceride (mg/dl) & $140.8 \pm 94$ & $80.8 \pm 31.3$ & $Z=2.385 p=0.017^{*}$ \\
\hline $\mathrm{HDL}(\mathrm{mg} / \mathrm{dl})$ & $35.4 \pm 12.9$ & $36.8 \pm 21.1$ & $Z=0.372 p=0.71$ \\
\hline LDL (mg/dl) & $100.5 \pm 39.4$ & $66.6 \pm 46.4$ & $Z=2.409 p=0.016^{*}$ \\
\hline DD (years) & $12.5 \pm 7.8$ & $8.4 \pm 8.2$ & $Z=1.76 p=0.078$ \\
\hline T2DM family history (\%) & $22 / 38(57.9)$ & $4 / 11(36.4)$ & $x^{2}=1.59 p=0.2$ \\
\hline Hypertension (\%) & $26 / 38(68.4)$ & $2 / 11(18.2)$ & $X^{2}=8.79 p=0.003^{*}$ \\
\hline
\end{tabular}

Bold indicates statistical significant result

$D D$ diabetes duration, $B M I$ body mass index, GHb glycated hemoglobin, $F P G$ fasting plasma glucose, $S B P$ systolic blood pressure, $D B P$ diastolic blood pressure, $H D L-c$ high-density lipoprotein cholesterol and $L D L$-c low density lipoprotein cholesterol

*Significant value at $P<0.05$ 
diplotype was observed only in patients without MS $(p=0.008)$. This finding suggests a possible protective role of the 122 as haplotype and homozygous diplotype in MS susceptibility (Table 3).

\section{Role of CAPN10 variants in obesity, hypertension, hypertriglyceridemia, total cholesterol, HDL-c and LDL-C}

The present study extends to investigate the role of the three CAPN10 variants in different clinical and biochemical parameters including (obesity, hypertension, hypertriglyceridemia, total cholesterol, HDL-c and LDL-c levels). Only a significant association was detected with obesity and total cholesterol level. Regarding obesity, high prevalence was observed among diabetes cases (79.6\%). Additionally, a possible protective role of the 122 haplotype was observed (OR 0.11, 95\%CI 0.02-0.72, $p=0.004)$. The $111 / 121$ and $122 / 122$ diplotypes demonstrated a high protective role for obesity with $p$ values of 0.009 and 0.004 , respectively, and the clinical parameters of the 111/121 diplotype carriers were compared with those other diplotype carriers. A significant lower BMI of 111/121 diplotype carriers than those with other diplotypes were reported $\left(28.3 \pm 5.6\right.$ vs. $31.7 \pm 4.7 \mathrm{~kg} / \mathrm{m}^{2}$, $p=0.047$ ).

Regarding total cholesterol level, the patients' group was classified according to the criterion of total cholesterol into groups: patients with high total cholesterol and patients with normal total cholesterol. This classification was based on the report of Adult Treatment Panels [13, 14]. Our results suggest that $111 / 111$ homozygous diplotype may have a possible increased risk of obtaining high cholesterol level with $(p=0.047)$.
By conducting the statistical analysis between the atrisk 111/111 diplotype carriers and other diplotypes carriers, patients with 111/111 diplotype showed significantly higher FPG $(274.4 \pm 95.5$ vs. $196.9 \pm 88.4 \mathrm{mg} / \mathrm{dl}$, $P=0.041)$ and GHb $(8.1 \pm 1.3$ vs. $6.9 \pm 1.7 \%, p=0.026)$ than those with other diplotypes carriers. In addition, the total cholesterol level of the 111/111 diplotype carriers found to be higher compared with the other diplotypes carriers but the results were not statistically significant $(p=0.101)$.

\section{Discussion}

In this study, we examined the association of T2DM and MS risk with CAPN10 variants (SNP-43, SNP-19 and $S N P-63)$ at the level of alleles, genotypes, haplotypes and haplotype combination. Genetic interference of CAPN10 with T2DM and MS susceptibility in this pilot study suggested that none of these SNPs individually or at the level of genotype was associated with T2DMamong our study cohorts. Moreover, for better understanding of the relation between CAPN10 and both T2DM and MS risk, we examined three loci haplotypes and related possible haplotype combinations. The comparable distribution of all observed haplotypes between diabetic and healthy control subjects was investigated.

In principle, our finding is in accordance with the findings of Horikawa et al. suggesting that these genetic variations are not a major factor in the occurrence of T2DM in Japanese, although they could yet be associated with various phenotypes of the disease [15]. Zhang et al. reported the negative association of $r s 2975760$ and rs3792267 SNP polymorphisms of CAPN10 with the

Table 3 Haplotype and diplotype distribution among patients with or without MS

\begin{tabular}{|c|c|c|c|c|c|c|c|}
\hline \multirow{2}{*}{$\begin{array}{l}\text { Haplotype or } \\
\text { diplotype }\end{array}$} & \multicolumn{2}{|l|}{ MS } & \multicolumn{2}{|c|}{ Without MS } & \multirow[t]{2}{*}{$x^{2}$} & \multirow[t]{2}{*}{$p$} & \multirow[t]{2}{*}{ OR $(95 \% \mathrm{Cl})$} \\
\hline & Freq & $\%$ & Freq & $\%$ & & & \\
\hline 111 & 37 & 48.7 & 9 & 40.9 & 3.59 & 0.058 & $8.2(0.5-260.4)$ \\
\hline 112 & 9 & 11.8 & 1 & 4.5 & 1.12 & 0.29 & $3.1(0.3-73.6)$ \\
\hline 121 & 19 & 25 & 5 & 22.7 & 0.07 & 0.79 & $1.2(0.3-5.6)$ \\
\hline 122 & 4 & 5.3 & 5 & 22.7 & 6.94 & $0.008^{*}$ & $0.14(0.02-0.9)$ \\
\hline 221 & 5 & 6.6 & 2 & 9.1 & 0.18 & 0.675 & $0.68(0.1-6.1)$ \\
\hline 222 & 1 & 1.3 & 0 & 0.0 & 0.3 & 0.587 & NA \\
\hline $111 / 111$ & 8 & 21.1 & 1 & 9.1 & 0.814 & 0.384 & $2.67(0.3-63.9)$ \\
\hline $111 / 112$ & 7 & 18.4 & 1 & 9.1 & 0.544 & 0.473 & $2.26(0.2-54.9)$ \\
\hline $111 / 121$ & 6 & 15.8 & 4 & 36.4 & 2.223 & 0.146 & $0.33(0.1-1.9)$ \\
\hline $111 / 122$ & 3 & 7.9 & 1 & 9.1 & 0.016 & 0.912 & $0.86(0.1-23.9)$ \\
\hline $111 / 221$ & 3 & 7.9 & 1 & 9.1 & 0.016 & 0.912 & $0.86(0.1-23.9)$ \\
\hline $121 / 221$ & 2 & 5.3 & 1 & 9.1 & 0.217 & 0.656 & $0.56(0.03-17.3)$ \\
\hline $122 / 122$ & 0 & 0.0 & 2 & 18.2 & 7.203 & $0.007^{*}$ & $0.0(0.0-1.14)$ \\
\hline
\end{tabular}

Bold indicates statistical significant result

Non-applicable data were not mentioned 
Table 4 CAPN10 haplotype combination (diplotype) associated with high T2DM risk among different populations

\begin{tabular}{|c|c|c|c|c|}
\hline Population & T2DM diplotypes & $p$ & OR $(95 \% \mathrm{Cl})$ & Study \\
\hline Mexican American & $112 / 121$ & NA & $2.8(1.23-6.34)$ & {$[6]$} \\
\hline Polish & $121 / 121$ & 0.038 & $1.93(1.03-3.54)$ & [20] \\
\hline Japanese & $111 / 221$ & 0.02 & $3.53(1.24-10.1)$ & [19] \\
\hline Korean & $111 / 121$ & 0.001 & $2.58(1.602-4.155)$ & {$[4]$} \\
\hline Tunisian & $121 / 221$ & 0.02 & $2.38(1.05-5.48)$ & {$[5]$} \\
\hline Egyptian & $111 / 112$ & 0.011 & $10.15(1.2-225.0)$ & The present study \\
\hline
\end{tabular}

Bold indicates statistical significant result

incidence of gestational diabetes mellitus [16]. In parallel, Tursinawati et al. suggested that Japanese subjects with CAPN10 SNP19 genotypes might have susceptibility of T2DM [17]. Interestingly, the 111/112 haplotype combination was significantly associated with a 10.15 fold increased risk of T2DM (OR 10.15, 95\% CI 1.2-225, $p=0.011)$. This at-risk diplotype $(111 / 112)$ observed by our study was also reported by Adak et al. who suggested that the possible risky role of the 111/112 among eastern Indian population $(p=0.05)$ [18].

Although Horikawa et al. was the first to show that the haplotype combination 112/121, defined by (SNP-43, SNP - 19 and SNP -63), is a "at- risk" combination, associated with a 2.8-, 2.55- and 4.97- fold higher T2DM risk in the Mexican-American, Finnish and German populations, respectively [5], our study did not find this high risk haplotype combination among the studied Egyptian cohort. Additionally, the most frequent diplotype 111/121 in this cohort of Egyptian population was found to be associated with increased risk of T2DM in the Korean population [19]. Different high risk diplotypes reported by different studies and their association with T2DM susceptibility are summarized in Table 4.

Our finding that the haplotype 122 and diplotype $122 / 122$ provide a protective role against both MS and obesity is a novel one. Although 111/121 diplotype was observed to be associated with a possible lower risk of obesity among our studied cohort, the 111/121 diplotype was associated with higher MS risk among Korean patients, (OR 1.927, 95\% CI 1.024-3.626, $p=0.042$ ) [11]. Our present finding agrees with the finding of Cheverud et al. on the association of CAPN10 with obesity and diabetes [21]. A association of CAPN10 with BMI among Tunisian population [5], The 1221 haplotype defined by (SNP-44, SNP -43, SNP -19 and SNP-63) which corresponds to the 221 haplotype defined by the currently studied SNPs was found to be associated with higher risk of intraabdominal obesity among Finnish population $(p=0.004)$ [21]. An association between SNP-19 associated with elevated body mass and glucose intolerance in Japanese population [19]. The diplotype 111/111 displayed significant risk for elevated levels of total cholesterol.

Our finding agrees with Daimon et al., reported that the CAPN10 genotype combination might be a risk factor for increased serum cholesterol [11]. Sakar et al. reported the association of CAPN10 (SNP-19) genetic polymorphism with T2DM in Bengali Hindu caste population [22].

\section{Conclusions}

T2DM is a multifactorial disease caused by both genetic as well as non-genetic environmental factors. Deep understanding of T2DM causes is important to create a balance between energy intake and output and other life style related factors. This study reported an evidence on the association of CAPN10 variants and T2DM, MS, obesity, and total cholesterol level among this cohort of Egyptian population. Enhanced sample size, study of other CAPN-10 SNPs along with other T2DM related genetic variants are recommended and will be investigated in the further studies.

\section{Abbreviations}

CAPN10: Gene encoding calpain 10; T2DM: Type 2 diabetes mellitus; MS: Metabolic syndrome; GWAs: Genome-wide association studies; GHb: Glycated hemoglobin; BMI: Body mass index.

\section{Acknowledgements}

We thank both the Clinical Genomic Center- Faculty of Medicine- Alexandria University and IGSR-Alexandria University- Egypt where the work was carried out by collaboration between them. Furthermore, we thank the patients and control persons who participated in this study.

\section{Authors' contributions}

We thank AS for putting the research's idea, SWE for collecting the samples, and carrying out all the experimental work and writing the manuscript, $\mathrm{MH}$ for designing the experiments, NM for providing the clinical data, HSK and AME for s interpretation of the results and reviewing the manuscript. All authors have read and approved the final manuscript.

Funding

Not applicable.

Availability of data and material

All data generated and/or analyzed during this study are included in this published article (and its supplementary information files). 


\section{Declarations}

\section{Ethics approval and consent to participate}

As a total of 102 individuals (49 type 2 diabetic patients and 53 healthy controls) were enrolled in this study from the Institute of Medical Research (IMR) Alexandria University, the study was approved by the ethical committee of Alexandria University. Moreover, an informed consent was obtained from each study participant verbally and this was approved by the ethics committee. The committee's reference number is not applicable. The written consent to publication was obtained directly from the patient (all of them in legal age).

\section{Consent for publication}

Not Applicable.

\section{Competing interests}

Not applicable.

\section{Author details}

'Division of Pharmaceutical Microbiology, Department of Pharmaceutics and Industrial Pharmacy, College of Pharmacy, Taif University, Taif, Kingdom of Saudi Arabia. ${ }^{2}$ Department of Biotechnology, Institute of Graduate Studies and Research (IGSR), Alexandria University, Alexandria 21526, Egypt. ${ }^{3}$ Pathology Department, Clinical Genomic Center, Faculty of Medicine, University of Alexandria, Alexandria, Egypt. ${ }^{4}$ Department of Internal Medicine, Medical Research Institute, Alexandria University, Alexandria, Egypt.

Received: 11 March 2021 Accepted: 1 October 2021

Published online: 25 February 2022

\section{References}

1. Padilla-Martínez F, Collin F, Kwasniewski M, Kretowski A (2020) Systematic review of polygenic risk scores for type 1 and type 2 diabetes. Int J Mol Sci 21:1703. https://doi.org/10.3390/ijms21051703

2. Abuhendi N, Qush A, Naji F, Abunada H, Al Buainain R (2019) Genetic polymorphisms associated with type 2 diabetes in the Arab world: a systematic review and meta-analysis. Diabetes Res Clin Pract 151:198-208. https://doi.org/10.1016/j.diabres.2019.03.037

3. Weedon MN, Schwarz PE, Horikawa Y, Iwasaki N, Illig T (2003) Meta-analysis and a large association study confirm a role for calpain-10 variation in type 2 diabetes susceptibility. Am J Hum Genet 73:1208-1212. https:// doi.org/10.1086/379285

4. Kang ES, Nam M, Kim HJ, Kim HJ, Myoung SM, Rhee Y, Ahn CW, Cha BS, Lee HCJ (2006) Haplotype combination of Calpain-10 gene polymorphism is associated with metabolic syndrome in type 2 diabetes. Diabetes Res Clin Pract 73:268-275. https://doi.org/10.1016/j.diabres.2006.01. 011

5. Ezzidi I, Mtiraoui N, Nemr R, Kacem M, Al-Khateeb G, Mahjoub T, Almawi WJD (2010) Variants within the calpain-10 gene and relationships with type 2 diabetes (T2DM) and T2DM-related traits among Tunisian Arabs. Diabetes Metab 36:357-362. https://doi.org/10.1016/j.diabet.2010.03.005

6. Horikawa Y, Oda N, Cox NJ, Li X, Orho-Melander M, Hara M, Hinokio Y, Lindner TH, Mashima H, Schwarz PEJ (2000) Genetic variation in the gene encoding calpain-10 is associated with type 2 diabetes mellitus. Nat Genet 26:163-175

7. Schäfer SA, Machicao F, Fritsche A, Häring H-U, Kantartzis KJD (2011) New type 2 diabetes risk genes provide new insights in insulin secretion mechanisms. Diabetes Res Clin Pract 2011(93):S9-S24. https://doi.org/10. 1016/S0168-8227(11)70008-0

8. Alberti K, Davidson MB, DeFronzo RA, Drash A, Genuth S, Harris MI, Kahn R, Keen H, Knowler WC, Lebovitz HJ (1998) Report of the expert committee on the diagnosis and classification of diabetes mellitus. Diabetes Care 21:S5-S19. https://doi.org/10.2337/diacare.20.7.1183

9. Gavin JR III, Alberti K, Davidson MB, DeFronzo RA (1997) Report of the expert committee on the diagnosis and classification of diabetes mellitus. Diabetes Care 1997(20):1183. https://doi.org/10.2337/diacare.20.7.118311

10. Deedwania PC, Hunninghake DB, Bays HE, Jones PH, Cain VA, Blasetto JW (2005) Effects of rosuvastatin, atorvastatin, simvastatin, and pravastatin on atherogenic dyslipidemia in patients with characteristics of the metabolic syndrome. Am J Cardiol 95:360-366. https://doi.org/10.1016/jamjcard. 2004.09.034

11. Daimon M, Oizumi T, Saitoh T, Kameda W, Yamaguchi H, Ohnuma H, Igarashi M, Manaka H, Kato TJ (2002) Calpain 10 gene polymorphisms are related, not to type 2 diabetes, but to increased serum cholesterol in Japanese. Diabetes Res Clin Pract 56:147-152. https://doi.org/10.1016/ S0168-8227(01)00372-2

12. Sambrook J, Fritsch EF, Maniatis T (1989) Molecular cloning: a laboratory manual. Cold Spring Harbor Laboratory Press, New York

13. Evans JC, Frayling TM, Cassell PG, Saker PJ, Hitman GA, Walker M, Levy JC, O'Rahilly S, Rao PV, Bennett AJ (2001) Studies of association between the gene for calpain-10 and type 2 diabetes mellitus in the United Kingdom. Am J Hum Genet 69:544-552. https://doi.org/10.1086/323315

14. Lorenzo C, Williams K, Hunt KJ, Haffner SM, Lorenzo C, Williams K, Hunt KJ, Haffner S (2007) The National Cholesterol Education Program-Adult Treatment Panel III, International Diabetes Federation, and World Health Organization definitions of the metabolic syndrome as predictors of incident cardiovascular disease and diabetes. Diabetes Care 30:8-13. https:// doi.org/10.2337/dc06-1414

15. Horikawa Y, Oda N, Yu L, Imamura S, Fujiwara K, Makino M, Seino Y, Itoh M, Takeda JJ (2003) variations in calpain-10 gene are not a major factor in the occurrence of type 2 diabetes in Japanese. J Clin Endocrinol Metab 88:244-247. https://doi.org/10.1210/jc.2002-020847

16. Zhang $X$, Shi C, Wei L, Sun F (2019) The association between the rs2975760 and rs3792267 single nucleotide polymorphisms of calpain 10 (CAPN10) and gestational diabetes mellitus. Int Med J Exp Clin Res 25:5137. https://doi.org/10.12659/MSM.914930

17. Tursinawati Y, Hakim RF, Rohmani A, Kartikadewi A, Sandra FJTIBJ (2020) CAPN10 SNP-19 is associated with susceptibility of type 2 diabetes mellitus: a Javanese case-control study. Indones Biomed J 12:109-114. https:// doi.org/10.18585/inabj.v12i2.984

18. Adak S, Sengupta S, Chowdhury S, Bhattacharyya MJ (2010) Co-existence of risk and protective haplotypes of calpain 10 gene to type 2 diabetes in the eastern Indian population. Diabetes Vasc Dis Res 7:63-68. https://doi. org/10.1177/1479164109351370

19. Shima Y, Nakanishi K, Odawara M, Kobayashi T, Ohta HJ (2003) Association of the SNP-19 genotype 22 in the calpain-10 gene with elevated body mass index and hemoglobin A1c levels in Japanese. Clin Chim Acta 336:89-96. https://doi.org/10.1016/S0009-8981(03)00320-6

20. Malecki MT, Moczulski DK, Klupa T, Wanic K, Cyganek K, Frey J, Sieradzki $J$ (2002) Homozygous combination of calpain 10 gene haplotypes is associated with type 2 diabetes mellitus in a Polish population. Eur J Endocrinol 146:695-699. https://doi.org/10.1194/jlr.M900128-JLR200

21. Cheverud JM, Fawcett GL, Jarvis JP, Norgard EA, Pavlicev M, Pletscher LS, Polonsky KS, Ye H, Bell Gl, Semenkovich CF (2010) Calpain-10 is a component of the obesity-related quantitative trait locus Adip1. J Lip Res 51:907-913. https://doi.org/10.1194/jlr.m900128

22. Sarkar P, Chatterjee D, Bandyopadhyay R (2020) Association of CAPN10 (SNP-19) genetic polymorphism and obesity with T2DM: a study on Bengali Hindu caste population. Int J Diabetes in Dev Ctries. https://doi. org/10.1007/s13410-020-00861-0

\section{Publisher's Note}

Springer Nature remains neutral with regard to jurisdictional claims in published maps and institutional affiliations. 